\title{
Hyposexuality in Men with Obstructive Sleep Apnea Syndrome
}

\author{
Jun Kyu Mun ${ }^{1}$, Eun Yeon Joo ${ }^{1,2}$ \\ ${ }^{1}$ Department of Neurology, Samsung Medical Center, Sungkyunkwan University School of Medicine, Seoul, \\ ${ }^{2}$ Neuroscience Center, Samsung Medical Center, Seoul, Korea
}

\author{
Received January 5, 2015 \\ Revised February 14, 2015 \\ Accepted March 7, 2015 \\ Address for correspondence \\ Eun Yeon Joo, MD, PhD \\ Department of Neurology, \\ Samsung Medical Center, \\ Sungkyunkwan University \\ School of Medicine, 81 Irwon-ro, \\ Gangnam-gu, Seoul 135-710, \\ Korea \\ Tel: $+82-2-3410-3597$ \\ Fax: +82-2-3410-0630 \\ E-mail: eunyeon1220.joo@ \\ samsung.com
}

Objectives: Hyposexuality is defined as diminished sexual drive or libido. There has been little research into the sexuality in patients with obstructive sleep apnea (OSA). We investigated the prevalence and relating factors for hyposexuality in OSA men. Methods: Consecutive 182 male (mean age 48.3 y) were enrolled who were newly diagnosed with OSA through polysomnography. All completed Symptom checklist90-Revised (SCL-90-R), Epworth Sleepiness Scale (ESS), Beck Depression Inventory (BDI), and Beck Anxiety Inventory (BAI). Subjects were divided into non-hyposexuality (score 0 ) and hyposexuality (score $\geq 1$ ) groups according to the question "Loss of sexual interest or pleasure" in SCL-90-R. Results: 110 of 182 subjects $(60.4 \%)$ answered hyposexuality (score $\geq 1$ ). Significant correlations were found between hyposexuality and following factors; age ( $\mathrm{rho}=0.248), \mathrm{BDI}(\mathrm{rho}=0.450), \mathrm{BAI}(\mathrm{rho}=0.410), \mathrm{ESS}(\mathrm{rho}=0.221)$, and percentage of non-REM stage $3(\mathrm{~N} 3 \%)$ (rho=-0.184). Apnea-hypopnea index was significantly correlated with nocturia ( $\mathrm{rho}=0.320)$, ESS $(\mathrm{r}=0.230), \mathrm{N} 1 \%(\mathrm{r}=0.596), \mathrm{N} 2 \%(\mathrm{r}=-0.540), \mathrm{N} 3 \%(\mathrm{r}=-0.195)$, and lowest oxygen saturation $(\mathrm{r}=-0.641)$. Comparing two groups, hyposexuality group showed significantly lowered total sleep time ( $380.2 \mathrm{~min}$ vs. $359.1 \mathrm{~min}$ ), and sleep efficiency ( $83 \%$ vs. $76 \%$ ). The severity of hyposexuality was correlated with BDI (rho=0.330), BAI ( $\mathrm{rho}=0.253)$, and N3\% (rho=-0.215) in subjects with hyposexuality. After controlling for age, polysomnographic parameters were not correlated with hyposexuality. Conclusions: About half of untreated OSA male subjects reported diminished libido. Age, daytime sleepiness, mood disorders, and decreased sleep quality were associated with hyposexuality. Of these, aging process was the most important factor for hyposexuality.

J Sleep Med 2015;12(1):7-12

\section{Introduction}

Obstructive sleep apnea syndrome (OSA) is a common sleep disorder affecting 4 to $9 \%$ of adult males and makes repetitive upper airway obstruction occurring hundreds of times in a night. ${ }^{1-3}$ Apnea related hypoxia triggers arousal from sleep. This induces sleep fragmentation.

Hyposexuality is defined as diminished sexual drive or libido, and may or may not be accompanied by erectile or orgasmic dysfunction. ${ }^{4}$ Sexuality is an important aspect of life and it is known to be intimately linked with sleep. It is already known that OSA leads to reversible neuroendocrine dysfunction, which is presented by decreased plasma luteinizing hormone (LH), testosterone, and sex hormone-binding globulin levels. ${ }^{5-7}$ Serum testosterone level rises during the rapid eye movement (REM) sleep period, especially in the first REM

This is an Open Access article distributed under the terms of the Creative Commons Attribution Non-Commercial License (http://creativecommons.org/licenses/by-nc/3.0) which permits unrestricted non-commercial use, distribution, and reproduction in any medium, provided the original work is properly cited. sleep. ${ }^{8}$ However, OSA related sleep fragmentation disrupt attenuation of the nocturnal rise of testosterone. ${ }^{9}$

To date, there has been no large population-based study of association between OSA and hyposexuality in South Korea. The present study is to investigate the prevalence of hyposexuality in OSA male and to explore the related factors for hyposexuality in those subjects.

\section{Methods}

\section{Subjects}

Patients who visited to the sleep clinic of Samsung Medical Center, Seoul, Korea from January 2014 to October 2014 were consecutively enrolled. All the patients were male between 18 and 81-year-old with history of sleep apnea and daytime sleepiness. They completed overnight polysomnography (PSG) and questionnaires. We defined OSA as 5 or more of apnea-hypopnea index (AHI) and presence of daytime sleepiness. Of total 206 patients, 8 patients were excluded because 
AHI was lower than 5. 16 patients who had uncontrolled metabolic disorders [hypertension (HTN), diabetes mellitus (DM), chronic renal disease], psychiatric disorders, critical illness, or other sleep disorders were also excluded.

\section{Polysomnography (PSG)}

All subjects were performed overnight PSG. PSG parameters were defined according to the American Academy of Sleep Medicine. ${ }^{10}$ Apnea was defined as a cessation of airflow through an airway for more than 10 seconds. Hypopnea was defined as a reduction in the amplitude of the respiratory flow signal of at least $50 \%$ for a minimum of $10 \mathrm{sec}$, followed by a $4 \%$ decrease in oxygen saturation or signs of physiological arousal. Electrooculography, electromyography, electroencephalography, respiration, and oxygen saturation were also recorded. Respiratory effort was measured by nasal thermistors and thoracoabdominal strain gauges. Pulse oximetry was used to record oxygen saturation. All procedures were performed by experienced technicians and PSG results were reviewed by sleep specialists.

\section{Questionnaires}

We used a question number 5 of Symptom checklist-90-Revised (SCL-90-R) to assess degree of hyposexuality. ${ }^{11}$ The question is "Loss of sexual interest or pleasure" and the degree includes from 0 (not at all) to 4 (extremely). Epworth Sleepiness Scale (ESS) was used to measure average daytime sleepiness. ${ }^{12}$ Score $\geq 9$ is considered to have a excessive daytime sleepiness. Beck Depression Inventory (BDI) and Beck Anxiety Inventory (BAI) were also assessed as a clinical information.

\section{Statistical analysis}

Continuous data are presented as mean \pm standard deviation or median and interquartile range, as appropriate. We compared clinical data, questionnaires, and PSG parameters between patients with hyposexuality and without hyposexuality using Student t test, Mann-Whitney U test. Pearson correlation analysis, Spearman correlation analysis, and Partial correlation anaylsis were used to analyze associations among hyposexuality, clinical data, and PSG parameters. Analysis was conducted using SPSS version 18.0 software (SPSS Inc., Chicago, IL, USA), and a $p<0.05$ was considered statistically significant.

\section{Results}

Over the half of the patients had a complaint of hyposexuality, 110 of 182 (60.4\%). Hyposexuality group was older (49.9 \pm 11.4 vs. $44.3 \pm 13.4 ; p=0.005)$, and higher score of ESS (10.4 \pm 5.0 vs. $8.5 \pm 3.7 ; p=0.013)$, BDI ( $10.0 \pm 5.9$ vs. $5.7 \pm 4.6$; $p<0.001)$, BAI (11.1 \pm 8.7 vs. $5.6 \pm 5.5 ; p<0.001)$ than non-hyposexuality group. Body mass index (BMI) and frequency of nocturia during sleep were not different between two groups (Table 1).

The data of PSG parameters are depicted in Table 2. Total sleep time (TST) $(359.0 \pm 69.5$ vs. $381.5 \pm 52.1 ; p=0.023)$ and

Table 1. Clinical characteristic of patients

\begin{tabular}{lccr}
\hline & $\begin{array}{c}\text { Non- } \\
\text { hyposexuality } \\
(\mathrm{n}=72)\end{array}$ & $\begin{array}{c}\text { Hyposexuality } \\
(\mathrm{n}=110)\end{array}$ & $p$-value \\
\hline Age (years) & $44.3 \pm 13.4$ & $49.9 \pm 11.4$ & 0.005 \\
Body mass index & $25.9 \pm 3.8$ & $25.5 \pm 2.8$ & 0.478 \\
Epworth sleepiness scale & $8.5 \pm 3.7$ & $10.4 \pm 5.0$ & 0.013 \\
Beck depression index & $5.7 \pm 4.6$ & $10.0 \pm 5.9$ & $<0.001$ \\
Beck anxiety index & $5.6 \pm 5.5$ & $11.1 \pm 8.7$ & $<0.001$ \\
Nocturia, n & $1.0[0-1.3]$ & $1.0[0-1.5]$ & 0.954 \\
\hline
\end{tabular}

Values are expressed as mean \pm standard deviation or IQR [interquartile range]. n: numbers

Table 2. Polysomnography parameters

\begin{tabular}{|c|c|c|c|}
\hline & $\begin{array}{c}\text { Non- } \\
\text { hyposexuality } \\
(\mathrm{n}=72)\end{array}$ & $\begin{array}{l}\text { Hyposexuality } \\
\qquad(\mathrm{n}=110)\end{array}$ & $p$-value \\
\hline $\mathrm{TIB}(\min )$ & $444.4 \pm 33.4$ & $436.2 \pm 64.2$ & 0.705 \\
\hline Total sleep time, min & $381.5 \pm 52.1$ & $359.0 \pm 69.5$ & 0.023 \\
\hline Sleep latency & $8.6 \pm 8.4$ & $8.2 \pm 7.0$ & 0.692 \\
\hline REM latency & $108.4 \pm 88.9$ & $100.9 \pm 54.1$ & 0.902 \\
\hline Sleep efficiency \% & $86.6 \pm 9.6$ & $79.8 \pm 12.6$ & 0.031 \\
\hline Arousal index & $29.0 \pm 15.5$ & $30.1 \pm 16.8$ & 0.722 \\
\hline N1\% & $22.9 \pm 12.2$ & $24.0 \pm 12.2$ & 0.535 \\
\hline $\mathrm{N} 2 \%$ & $53.0 \pm 10.1$ & $53.7 \pm 11.7$ & 0.616 \\
\hline N3\% & $4.1 \pm 5.4$ & $2.5 \pm 4.7$ & 0.100 \\
\hline REM \% & $20.1 \pm 5.7$ & $19.6 \pm 6.6$ & 0.416 \\
\hline WASO, min & $60.8 \pm 48.6$ & $65.3 \pm 45.4$ & 0.225 \\
\hline AHI & $34.4 \pm 21.4$ & $30.5 \pm 21.5$ & 0.149 \\
\hline RDI & $36.6 \pm 20.9$ & $33.4 \pm 20.6$ & 0.295 \\
\hline REM RDI & $35.6 \pm 22.8$ & $35.2 \pm 20.7$ & 0.796 \\
\hline REM arousal index & $23.4 \pm 16.0$ & $24.9 \pm 17.0$ & 0.560 \\
\hline PLMD index & $7.6 \pm 13.3$ & $7.5 \pm 17.0$ & 0.757 \\
\hline $\begin{array}{l}\text { Movement arousal } \\
\text { index }\end{array}$ & $0.7 \pm 1.5$ & $0.8 \pm 1.5$ & 0.932 \\
\hline Lowest $\mathrm{O}_{2}$ sat $\%$ & $82.2 \pm 6.9$ & $83.5 \pm 6.5$ & 0.138 \\
\hline
\end{tabular}

Values are expressed as mean \pm standard deviation. TIB: time in bed, REM: rapid eye movement, N1: non-REM stage 1, N2: nonREM stage 2, N3: non-REM stage 3, WASO: wake after sleep onset, AHI: apnea-hypopnea index (number of apnea and hypopnea/ $h$ of sleep), RDI: respiratory disturbance index, PLMD: periodic limb movement disorder 
sleep efficiency $\%$ ( $79.8 \pm 12.6$ vs. $86.6 \pm 9.6 ; p=0.031)$ were decreased in hyposexuality group. The other PSG parameters including time in bed, arousal index, respiratory disturbance index, AHI, wake after sleep onset (WASO), percentage of sleep stages, and lowest oxygen saturation were not significantly different between groups.

In a whole patients analysis, the severity of hyposexuality showed positive correlation with BDI (rho $=0.450 ; p<0.001$ ), BAI (rho $=0.410 ; p<0.001$ ), and ESS (rho $=0.221 ; p=0.003$ ). A percentage of non-REM sleep stage $3(\mathrm{~N} 3 \%)$ was negatively correlated with hyposexuality (rho=-0.184; $p=0.013$ ) (Fig. 1). Similar patterns were appeared in the patients with hyposexuality. BDI (rho $=0.330 ; p<0.001)$ and BAI ( $r h o=0.253 ; p=$ 0.008 ) were shown positive correlation, and N3\% was seen negative correlation with hyposexuality (rho $=-0.215 ; p=$ 0.024 ) (Fig. 2). However, after controlling for age factor, the severity of hyposexuality presented positive correlation only with BAI ( $\mathrm{r}=0.350 ; p=0.010)$, $\mathrm{BDI}(\mathrm{r}=0.439 ; p=0.001)$, and ESS $(\mathrm{r}=0.292 ; p=0.034)$ in whole patients group (Table 3$)$. And in hyposexuality group, there were no significant correlation of the severity of hyposexuality with clinical and sleep parameters.

In comparison of AHI with PSG parameters and questionnaires, a frequency of nocturia $(\mathrm{r}=0.363 ; p<0.001)$, ESS $(\mathrm{r}=$ $0.230 ; p=0.001$ ), and percentage of non-REM sleep stage 1 $(\mathrm{N} 1 \%)(\mathrm{r}=0.596 ; p<0.001)$ had positive correlation with AHI. On the other hand, percentage of non-REM sleep stage 2 $(\mathrm{N} 2 \%)(\mathrm{r}=-0.540 ; p<0.001)$ and $\mathrm{N} 3 \%(\mathrm{r}=-0.195 ; p=0.006)$ were

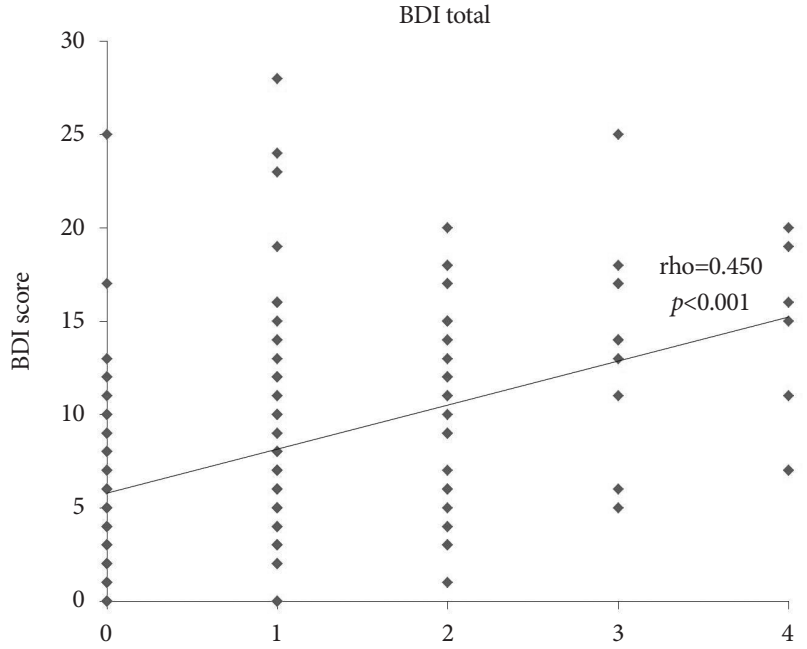

A

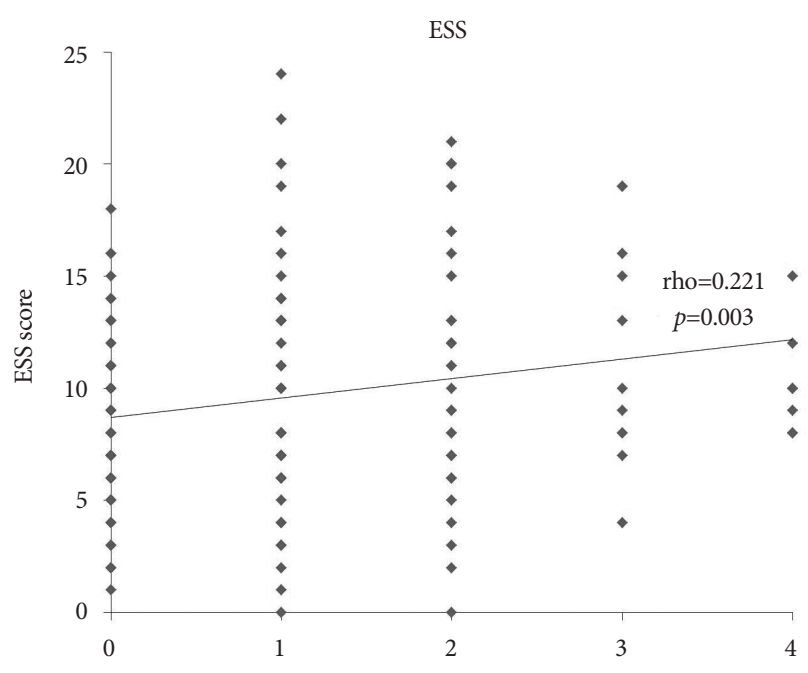

C

Figure 1. Correlation analysis between hyposexuality and clinical/polysomnography parameters in all patients. Severity of hyposexuality was positively correlated with BDI, BAI, and ESS scores (A-C). However, N3\% showed negative correlation to hyposexuality (D). BDI: Beck Depression Inventory, BAI: Beck Anxiety Inventory, ESS: Epworth Sleepiness Scale, N3\%: percentage of non-REM stage 3, SCL-90: Symptom checklist-90.

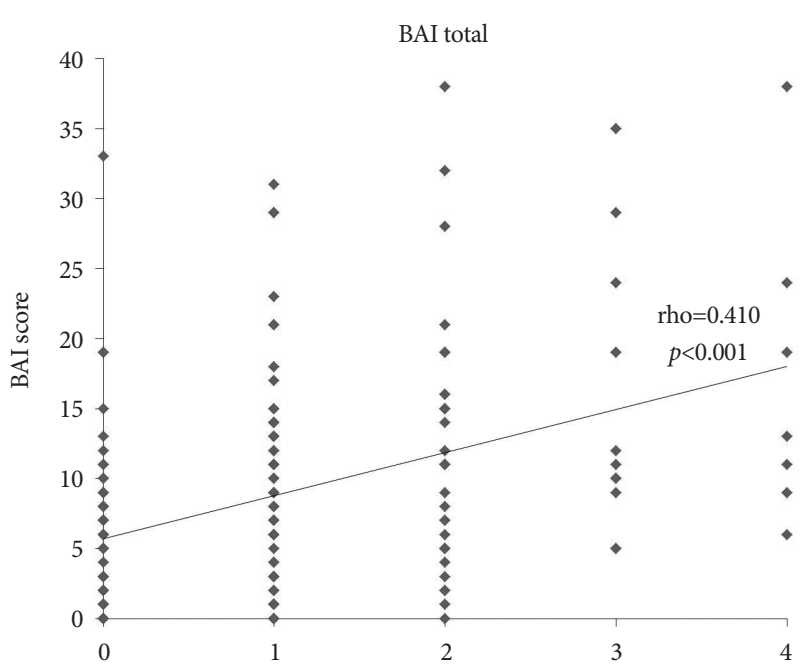

B

SCL-90, Q5 score

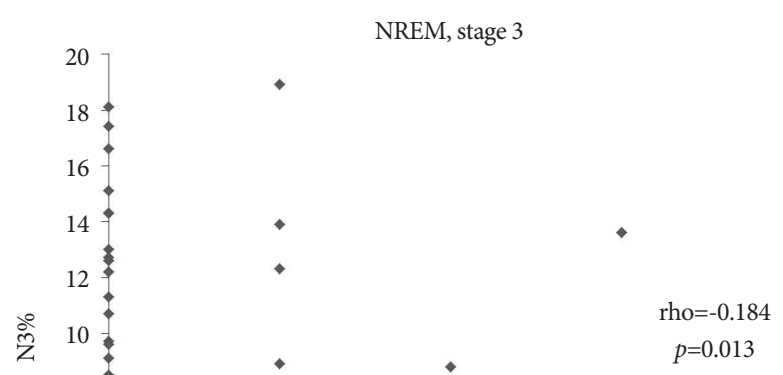




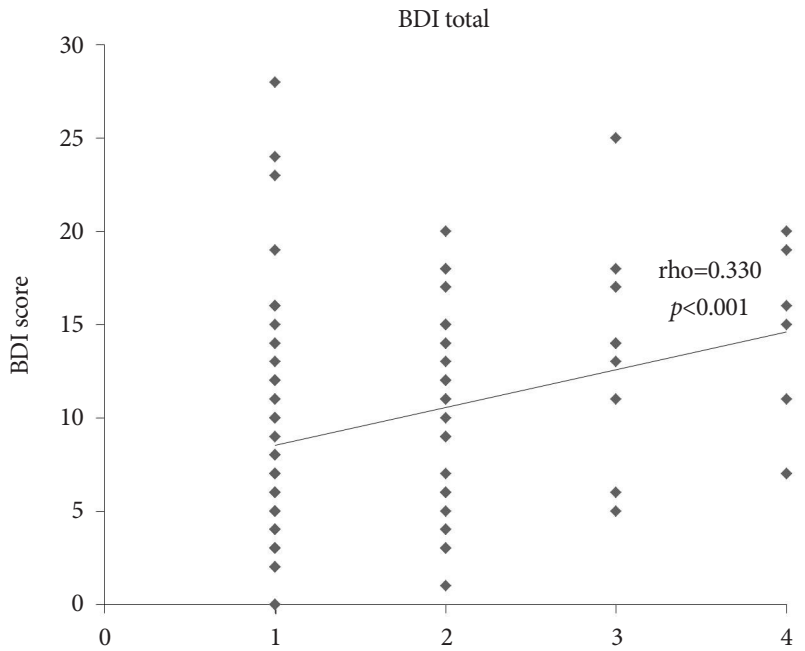

A

SCL-90, Q5 score

ESS

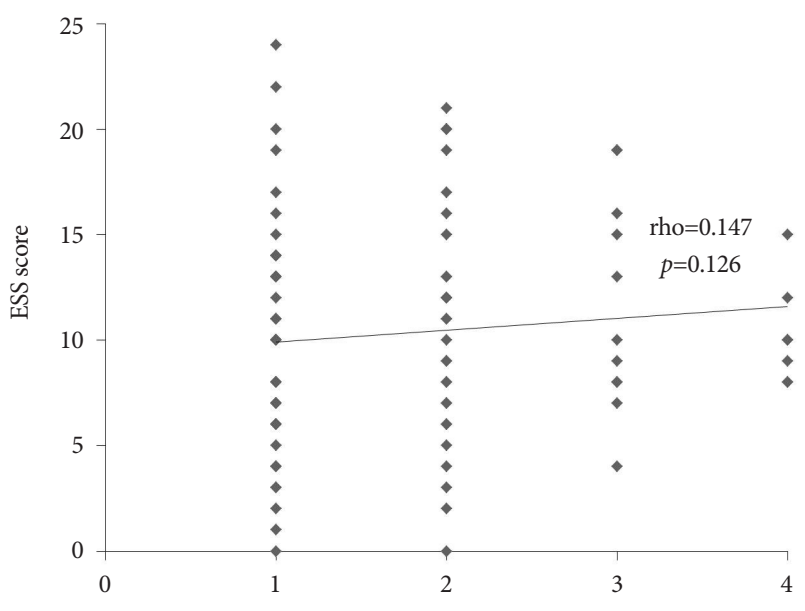

C

SCL-90, Q5 score

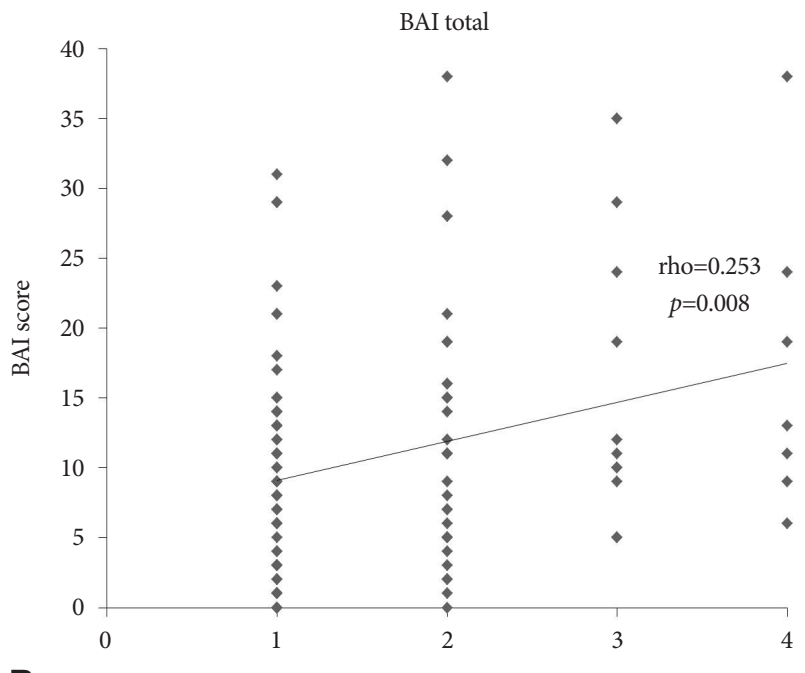

SCL-90, Q5 score

NREM, stage 3

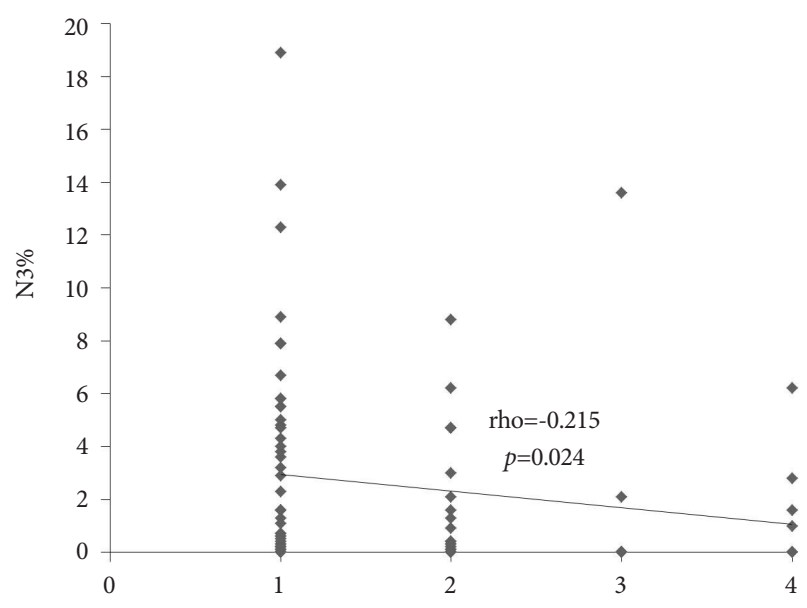

SCL-90, Q5 score

Figure 2. Correlation analysis between hyposexuality and clinical/polysomnography parameters in hyposexuality group. Hyposexuality group presented positive correlation of severity of hyposexuality to BDI, BAI (A, B). ESS showed no significant correlation with hyposexuality (C). Decreased N3\% is correlated with hyposexuality (D). BDI: Beck Depression Inventory, BAI: Beck Anxiety Inventory, ESS: Epworth Sleepiness Scale, N3\%: percentage of non-REM stage 3, SCL-90: Symptom checklist-90.

negatively correlated with AHI (Table 4).

\section{Discussion}

This retrospective study focuses on hyposexuality in male with untreated OSA. First of all, we excluded patients with metabolic syndrome which are related to OSA. Because uncontrolled HTN and DM are known causes to make hyposexuality. Hypertension related atherosclerotic process damage to vascular and perivascular genital tissues. ${ }^{13,14}$ Diabetes is associated with all domains of sexual functions including decreased sexual drive, erectile dysfunction, and sexual satisfaction..$^{15}$ These are possibly related with the development of peripheral neuropathy, abnormal neural control, vascular in- sufficiency and psychological problems have been implicated in decreased sexual desire. ${ }^{15,16}$

We demonstrated that untreated OSA leads to hyposexuality in over half of male patients (60.4\%) and poor sleep quality was correlated with decreased libido. TST and percentage of sleep efficiency (SE\%) were decreased in hyposexuality group. In some previous studies, apneic patients tend to have lower TST, which was related to less SE\% and higher daytime sleepiness. Because OSA related recurrent flow-limited breathing and episodic oxygen desaturation that is terminated with arousals. ${ }^{17,18}$

We also found that the less slow wave sleep including N3, the more severe hyposexuality were presented. This pattern is similar in both whole OSA patients and hyposexuality group 
Table 3. Correlation between hyposexuality and clinical/polysomnography parameters in all patients after controlling for age*

\begin{tabular}{lcc}
\hline & \multicolumn{2}{c}{ Severity of hyposexuality ${ }^{\dagger}$} \\
\cline { 2 - 3 } & r-value & $p$-value \\
\hline BDI & 0.439 & 0.001 \\
BAI & 0.350 & 0.010 \\
ESS & 0.292 & 0.034 \\
N3\% & -0.065 & 0.393 \\
\hline
\end{tabular}

*All statistical test were performed using Partial correlation controlled for age, ${ }^{\dagger}$ The question number 5 in SCL-90-R "Loss of sexual interest or pleasure" from 0 (not at all) to 4 (extremely). BAI: Beck Anxiety Inventory, BDI: Beck Depression Inventory, ESS: Epworth Sleepiness Scale, N3\%: percentage of non-REM stage 3, SCL-90-R: Symptom checklist-90-Revised

analysis. There were no significant difference of WASO and arousal index between two groups in our study. However, the mean values were much higher than normal range. These are related to visible or non-visible arousal and produce sleep fragmentation. ${ }^{19,20}$ That is to reduce slow wave sleep, sleep efficiency and increase N1\%.

In some previous studies, the reduced amounts of $\mathrm{LH}$ and testosterone level is associated with OSA related sleep fragmentation and sexual dysfunction. ${ }^{8,9}$ Their significant association suggest that the pituitary-gonadal dysfunction is a consequence of OSA. ${ }^{6}$ In another study demostrated that male with lower testosterone levels had lower sleep efficiency, increased nocturnal awakenings and less time in slow wave sleep. ${ }^{21}$ Our results of low sleep efficiency and negative correlation of N3\% with hyposexuality are matched with these studies.

When we control the age factor, BDI, BAI, and ESS were remained significant positive correlation with the severity of hyposexuality. On the other hand, PSG parameters were not correlated with the hyposexuality. These results could be come from some reasons. First of all, age is a core factor that leads to hyposexuality. In previous studies, age of patients affect negatively to sexual drive. Laumann et al. reported that increasing age for men is positively associated with erection problems and decreased sexual drive. ${ }^{22} 40$ to 60 years men presented 3 times as likely to experience low sexual desire in comparison to men aged 18 to 29 years. Sternbach et al. reported that age-associated decline of testosterone level diminished libido. As men age, the free testosterone level declines approximately $1 \%$ per year. In this study, administration of testosterone improved in 70 to $80 \%$ of patients with hyposexuality. ${ }^{23,24}$ Second, patient numbers were relatively small. Third, the questionnaire used for patients grouping was relatively crude. SCL-90-R classified the degree of hyposexuality according to patients' subjective opinion. Thus, more objective and sensitive questionnaires are needed in further studies.

In respect of AHI, it had positive correlation with nocturia.
Table 4. Correlation between $\mathrm{AHI}$ and sleep parameters*

\begin{tabular}{lcc}
\hline & \multicolumn{2}{c}{$\mathrm{AHI} / \mathrm{h}$} \\
\cline { 2 - 3 } & r-value & $p$-value \\
\hline Nocturia $^{\dagger}$ & 0.363 & $<0.001$ \\
$\mathrm{ESS}$ & 0.230 & 0.001 \\
$\mathrm{~N} 1 \%$ & 0.596 & $<0.001$ \\
$\mathrm{~N} 2 \%$ & -0.540 & $<0.001$ \\
$\mathrm{~N} 3 \%$ & -0.195 & 0.006 \\
Lowest $\mathrm{O}_{2}$ saturation & -0.641 & $<0.001$ \\
\hline
\end{tabular}

*All statistical test were performed using Pearson correlation except nocturia, ${ }^{\dagger}$ Spearman correlation was used. AHI: apnea-hypopnea index, N1: non-REM stage 1, N2: non-REM stage 2, N3: nonREM stage 3, ESS: Epworth Sleepiness Scale

Nocturia was defined as two or more voids per night. In other studies, nocturia was found in about $40 \%$ of OSA patients and the AHI was higher in patients with nocturia than in those without it, even in less than 50 years of age. ${ }^{25}$ Various investigations suggested that an increased atrial natriuretic peptide (ANP) release is related to nocturia. ${ }^{26,27}$ Low oxygen saturation and right atrial stretching secondary to increased intrathoracic pressure could be possible causes for increased ANP secretion in OSA. ${ }^{28,29}$ It has been known that the severity of AHI was associated with sleep fragmentation. This makes shift of slow wave sleep to non-REM stage 1 (N1) and excessive daytime sleepiness. ${ }^{30,31}$ Our correlation analysis of AHI also presented same results (Table 4).

Depression and anxiety are causes for sexual dysfunction. Depression is presented with loss of interest, reduction in energy, and inability to experience pleasure. These symptoms are expected to produce difficult sexual relationships. Hyposexuality was reported by over $70 \%$ of patients with depression and anxiety. ${ }^{32,33}$ Our results of BDI and BAI were significantly higher in patients with hyposexuality.

There is a limitation in this study. We used only one questionnaire, the question number 5 of SCL-90, to evaluate the severity of hyposexuality. However, in previous studies, loss of sexual drive was measured by question number 5 of SCL90-R. Karp et al. showed that both loss-of-libido items of Hamilton Rating Scale for Depression-16 and SCL-90 presented similar correlation result to assess hyposexuality. ${ }^{34}$ Other studies also used the SCL-90 to evaluate sexual life. ${ }^{35,36}$ Therefore, the question 5 of SCL- 90 can be used to assess degree of hyposexuality.

In conclusion, decreased sleep quality significantly reduce sexual drive in untreated OSA male. The most important factor that associated with hyposexuality is aging process. Further investigations will be required to identify an improvement of hyposexuality in treated OSA patients and what are additional tests or questionnaires to confirm their sexual problems. 


\section{Acknowledgments}

This research was supported by Basic Science Research Program through the National Research Foundation of Korea (NRF) funded by the Ministry of Science, ICT \& Future Planning, Republic of Korea (No. 2014R1A1A3049510) and by Samsung Biomedical Research Institute grant (\#OTX0002111).

\section{REFERENCES}

1. Frey WC, Pilcher J. Obstructive sleep-related breathing disorders in patients evaluated for bariatric surgery. Obes Surg 2003;13:676-683.

2. Kim J, In K, Kim J, et al. Prevalence of sleep-disordered breathing in middle-aged Korean men and women. Am J Respir Crit Care Med 2004;170:1108-1113.

3. Peppard PE, Young T, Palta M, Dempsey J, Skatrud J. Longitudinal study of moderate weight change and sleep-disordered breathing. JAMA 2000;284:3015-3021.

4. Blumer D. Hypersexual episodes in temporal lobe epilepsy. Am J Psychiatry 1970;126:1099-1106.

5. Grunstein RR, Handelsman DJ, Lawrence SJ, Blackwell C, Caterson ID, Sullivan CE. Neuroendocrine dysfunction in sleep apnea: reversal by continuous positive airways pressure therapy. J Clin Endocrinol Metab 1989;68:352-358.

6. Luboshitzky R, Aviv A, Hefetz A, et al. Decreased pituitary-gonadal secretion in men with obstructive sleep apnea. J Clin Endocrinol Metab 2002;87:3394-3398.

7. Santamaria JD, Prior JC, Fleetham JA. Reversible reproductive dysfunction in men with obstructive sleep apnoea. Clin Endocrinol (Oxf) 1988;28:461-470.

8. Luboshitzky R, Herer P, Levi M, Shen-Orr Z, Lavie P. Relationship between rapid eye movement sleep and testosterone secretion in normal men. J Androl 1999;20:731-737.

9. Luboshitzky R, Zabari Z, Shen-Orr Z, Herer P, Lavie P. Disruption of the nocturnal testosterone rhythm by sleep fragmentation in normal men. J Clin Endocrinol Metab 2001;86:1134-1139.

10. Ruehland WR, Rochford PD, O’Donoghue FJ, Pierce RJ, Singh P, Thornton AT. The new AASM criteria for scoring hypopneas: impact on the apnea hypopnea index. Sleep 2009;32:150-157.

11. Derogatis LR, Unger R. Symptom Checklist-90-Revised. In: Weiner IB, Craighead WE. The Corsini Encyclopedia of Psychology. New Jersey: John Wiley \& Sons, Inc., 2010.

12. Johns MW. Daytime sleepiness, snoring, and obstructive sleep apnea. The Epworth Sleepiness Scale. Chest 1993;103:30-36.

13. Bansal S. Sexual dysfunction in hypertensive men. A critical review of the literature. Hypertension 1988;12:1-10.

14. Manolis A, Doumas M, Viigimaa M, Narkiewitz K. Hypertension and sexual dysfunction. European Society of Hypertension Scientific Newsletter: Update on Hypertension Management 2007;8.

15. Burke JP, Jacobson DJ, McGree ME, et al. Diabetes and sexual dysfunction: results from the Olmsted County study of urinary symptoms and health status among men. J Urol 2007;177:1438-1442.

16. Zemel P. Sexual dysfunction in the diabetic patient with hypertension. Am J Cardiol 1988;61:27H-33H.

17. Patil SP, Schneider H, Schwartz AR, Smith PL. Adult obstructive sleep apnea: pathophysiology and diagnosis. Chest 2007;132:325-337.

18. Sauter C, Asenbaum S, Popovic R, et al. Excessive daytime sleepiness in patients suffering from different levels of obstructive sleep apnoea syn- drome. J Sleep Res 2000;9:293-301.

19. Fung MM, Peters K, Redline S, et al. Decreased slow wave sleep increases risk of developing hypertension in elderly men. Hypertension 2011;58:596-603.

20. Martin SE, Wraith PK, Deary IJ, Douglas NJ. The effect of nonvisible sleep fragmentation on daytime function. Am J Respir Crit Care Med 1997;155:1596-1601.

21. Barrett-Connor E, Dam TT, Stone K, et al. The association of testosterone levels with overall sleep quality, sleep architecture, and sleep-disordered breathing. J Clin Endocrinol Metab 2008;93:2602-2609.

22. Laumann EO, Paik A, Rosen RC. Sexual dysfunction in the United States: prevalence and predictors. JAMA 1999;281:537-544.

23. Schiavi RC, Rehman J. Sexuality and aging. Urol Clin North Am 1995; 22:711-726

24. Sternbach H. Age-associated testosterone decline in men: clinical issues for psychiatry. Am J Psychiatry 1998;155:1310-1318.

25. Moriyama Y, Miwa K, Tanaka H, Fujihiro S, Nishino Y, Deguchi T. Nocturia in men less than 50 years of age may be associated with obstructive sleep apnea syndrome. Urology 2008;71:1096-1098.

26. Krieger J, Laks L, Wilcox I, et al. Atrial natriuretic peptide release during sleep in patients with obstructive sleep apnoea before and during treatment with nasal continuous positive airway pressure. Clin Sci (Lond) 1989;77:407-411

27. Lin CC, Tsan KW, Lin CY. Plasma levels of atrial natriuretic factor in moderate to severe obstructive sleep apnea syndrome. Sleep 1993;16:3739.

28. Kita H, Ohi M, Chin K, et al. The nocturnal secretion of cardiac natriuretic peptides during obstructive sleep apnoea and its response to therapy with nasal continuous positive airway pressure. J Sleep Res 1998; 7:199-207.

29. Krieger J, Follenius M, Sforza E, Brandenberger G, Peter JD. Effects of treatment with nasal continuous positive airway pressure on atrial natriuretic peptide and arginine vasopressin release during sleep in patients with obstructive sleep apnoea. Clin Sci (Lond) 1991;80:443-449.

30. Bennett LS, Barbour C, Langford B, Stradling JR, Davies RJ. Health status in obstructive sleep apnea: relationship with sleep fragmentation and daytine sleepiness, and effects of continuous positive airway pressure treatment. Am J Respir Crit Care Med 1999;159:1884-1890.

31. Morrell MJ, Finn L, Kim H, Peppard PE, Badr MS, Young T. Sleep fragmentation, awake blood pressure, and sleep-disordered breathing in a population-based study. Am J Respir Crit Care Med 2000;162:2091-2096.

32. Baldwin DS. Depression and sexual dysfunction. Br Med Bull 2001;57: 81-99.

33. Laurent SM, Simons AD. Sexual dysfunction in depression and anxiety: conceptualizing sexual dysfunction as part of an internalizing dimension. Clin Psychol Rev 2009;29:573-585.

34. Karp JF, Frank E, Ritenour A, McEachran A, Kupfer DJ. Imipramine and sexual dysfunction during the long-term treatment of recurrent depression. Neuropsychopharmacology 1994;11:21-27.

35. Poggiogalle E, Di Lazzaro L, Pinto A, Migliaccio S, Lenzi A, Donini LM. Health-related quality of life and quality of sexual life in obese subjects. Int J Endocrinol 2014;2014:847871.

36. Schiavi RC, White D, Mandeli J, Levine AC. Effect of testosterone administration on sexual behavior and mood in men with erectile dysfunction. Arch Sex Behav 1997;26:231-241. 